Perspective

\title{
A Prospective Way to Achieve Ballistic Impact Resistance of Lightweight Magnesium Alloys
}

\author{
Abdul Malik ${ }^{1,2}$, Faisal Nazeer ${ }^{1,2}$ and Yangwei Wang ${ }^{2, *(\mathbb{D}}$ \\ 1 School of Mechanical Engineering, Dongguan University of Technology, Dongguan 523808, China; \\ abdulmalik0001@yahoo.com (A.M.); faisalnazeer221@gmail.com (F.N.) \\ 2 School of Material Science and Engineering, Beijing Institute of Technology, Beijing 100081, China \\ * Correspondence: wangyangwei@bit.edu.cn
}

Citation: Malik, A.; Nazeer, F.; Wang, Y. A Prospective Way to Achieve

Ballistic Impact Resistance of

Lightweight Magnesium Alloys.

Metals 2022, 12, 241. https://

doi.org/10.3390/met12020241

Academic Editor: Talal Al-Samman

Received: 8 December 2021

Accepted: 24 January 2022

Published: 27 January 2022

Publisher's Note: MDPI stays neutral with regard to jurisdictional claims in published maps and institutional affiliations.

Copyright: (C) 2022 by the authors. Licensee MDPI, Basel, Switzerland. This article is an open access article distributed under the terms and conditions of the Creative Commons Attribution (CC BY) license (https:// creativecommons.org/licenses/by/ $4.0 /)$.

\begin{abstract}
The ballistic impact resistance of lightweight magnesium alloys is an eye-catching material for the military and aerospace industries, which can decrease the cost of a project and the fuel consumption. The shockwave mitigation ability of a magnesium alloy is 100 times stronger than an aluminum alloy; nonetheless, ballistic impact resistance has still not been achieved against blunt and API projectiles. The major obstacles are the low hardness, low mechanical strength, basal texture and strain hardening ability under loading along the normal direction of the sheet. The high yield strength and ultimate strength can be achieved for a specific loading condition (tensile or compression) by adjusting the texture in magnesium alloys. The projectile impact along the normal direction in a strong basal-textured magnesium alloy can only produce a slip-induced deformation or minor twinning activity. Here, we propose a practical technique that can be valuable for altering the texture from c-axes / / ND to c-axes / /ED or TD, and can produce high strain hardening and high strength through a twinning and de-twinning activity. Subsequently, it can improve the ballistic impact resistance of magnesium alloys. The effect of the technique on the evolution of the microstructure and possible anticipated deformation mechanisms after ballistic impact is proposed and discussed.
\end{abstract}

Keywords: $M g$ alloys; pre-compression; texture; hardness; ballistic performance

\section{Introduction}

Over the years, scientists have worked on the development of next-generation lightweight materials for military applications. China and the United States military are working on the ballistic impact behavior of different metals, ceramics and glass materials. Most specifically, steel [1], aluminum ( $\mathrm{Al}$ ) [2] and titanium (Ti) [3] have been extensively employed for ballistic impact resistance against different projectiles. However, the high density and high fuel consumption led to an increase in the cost of the application and restricted their broad use. The other potential reason is the high $\mathrm{CO}_{2}$ emission into the environment. Therefore, uses of lightweight materials are important to reduce the cost of the project and $\mathrm{CO}_{2}$ emission into the environment. One of the prospective replacements is the magnesium $(\mathrm{Mg})$ alloy, because the density $\left(\rho \sim 1.78 \mathrm{~g} \mathrm{~cm}^{-3}\right)$ of $\mathrm{Mg}$ is $2 / 3$ of the density of $\mathrm{Al}$ and $1 / 4$ of the density of steel [4,5].

$M g$ alloys are comprised of a hexagonal close-packed crystal structure [6,7]. Owing to a low slip activity and twinning dependencies on the strain path loading, these alloys exhibit an anisotropic mechanical behavior [8,9]. Therefore, plastic deformation during the projectile impact is one of the important issues in thermomechanically processed $\mathrm{Mg}$ alloys. A severe and more complex deformation during impact can provide more resistance against the stress-energy and, hence, targeted material can facilitate more resistance and may be intact inside of it. The mechanical strength of $\mathrm{Mg}$ alloys without rare-earth elements is roughly $<400 \mathrm{MPa}$ under tensile or compressive loading [8,10-13]. In addition, the hardness of the material is roughly $<90 \mathrm{HV}[14,15]$. It is believed that the mechanical strength with 
a large elongation to fracture can absorb energy in the radial direction and the bottom of the crater; contrarily the high hardness controls the depth of penetration $(D O P)$. However, in $M g$ alloys, another important parameter is the strong basal-textured development after rolling/extrusion. The exposure direction of the impact on the sheet is the normal direction $(N D)$. Therefore, crystallographic orientations (c-axes//ND) can only provide a slip-induced deformation or minor twinning activity when it is subjected to loading along the ND. It has also been reported that the propensity of the dislocation and volume expedite with the decrease in grain size, whilst a transition from the slip to twinning occurs with an increase in grain size [16]. This is attributed to the twin interface energy $\left(84-122 \mathrm{~mJ} / \mathrm{m}^{3}\right)$, which increases with a decrease in the grain size.

It is obvious that an $M g$ alloy only provides basal and prismatic slip systems which have an $<a>$ type Burgers vector, while the other non-basal $<c+a>$ type of slips (pyramidal I and II) requires very high critical resolve shear stresses (CRSS) [17,18]. Therefore, the low-slip activity and no twinning/less twinning activity in basal-textured $M g$ alloys have provided a low absorption capacity and led to early cracks and even exhibited catastrophic failure $[19,20]$. Thus, loading along the $N D$ in a basal-textured (c-axes//ND) $M g$ alloy restricts the stain hardening and high absorption capacity. In short, the low hardness, average strength, and basal texture (c-axes / / ND) in $M g$ alloys displays the low ballistic impact resistance, or the projectile completely perforates through the targeted material.

The shape of the projectile, nose, speed, and type have a big influence on the DOP. Zou et al. [21-24] used different velocities $(0.5 \mathrm{~km} / \mathrm{s}, 4 \mathrm{~km} / \mathrm{s}$, and $5 \mathrm{~km} / \mathrm{s})$ and different projectiles (2017 Al ball, GCr15) on die-casted $A M 60 B \mathrm{Mg}$ alloys; the projectile was intact inside the targeted material. The velocities of the projectiles were high enough and met the requirement of aerospace applications. Zhang et al. [25] studied the deformation behavior of an $M g-A l-Z n$ alloy against a GCr15 projectile with an impact velocity of $900 \mathrm{~m} / \mathrm{s}$, and reported that the projectile was stopped inside the target material. Similarly, Zhang et al. [26] also studied the ballistic impact behavior of a $M g-A l-M n$ sheet against a GCr15 projectile under a velocity of $833 \mathrm{~m} / \mathrm{s}$. Most recently, Zhang et al. [27] conducted an impact test by using a $2017-A l$ ball against the $A Z 31 B M g$ alloy under a hypervelocity of $1.6-5 \mathrm{~km} / \mathrm{s}$, and reported that the $D O P$ is linked to the speed of the projectile as shown in Figure $1 \mathrm{a}-\mathrm{i}$. However, for military applications, the standardized $7.62 \mathrm{~mm}$ projectile with a different nose (blunt and $A P I$ ) was required. In another study, Shi et al. [28] conducted a ballistic impact test by using $7.62 \mathrm{~mm} T 12$ steel on a forged $M g-G d-Y-Z r$ (wt.\%) alloy but at a low velocity of $400 \mathrm{~m} / \mathrm{s}$. One of the projectiles completely perforated, but the other one stayed intact at the rear edge of the sheet. Abdullah et al. [19] used a Parabellum and NATO projectiles against $A Z 31$ and $A Z 31+P b M g$ alloys, and showed that the $A Z 31+1 \% P b$ exhibited a ballistic resistance against the Parabellum projectile under a velocity of $\sim 435 \mathrm{~m} / \mathrm{s}$. However, the NATO projectile fully perforated the targeted materials. Malik et al. [17] used a standard $7.62 \mathrm{~mm}$ soft steel core projectile at a standard velocity of $830 \mathrm{~m} / \mathrm{s}$. The projectile completely perforated, and onion-shaped concentric rings were formed at the rear view of the material, which exhibited catastrophic failure as shown in Figure $1 \mathrm{j}-\mathrm{m}$.

The hardness of the $M g$ alloys was very low compared to the $A l$ alloys [2,29-31]. It is obvious that the hardness controlled the DOP, while the high mechanical strength and high elongation absorbed the stress-energy carried by the projectile. Recently, spray-formed and extruded $A l$ 7055-T6, 6061-T6511, and 7A52-T6 Al alloys exhibited a higher mechanical response [2,30-32]. Among them, Al 7075-T6 exhibited a very high mechanical strength (YS 690 MPa and UTS 720 MPa). These values were much higher compared to $\mathrm{Mg}$ alloys. Therefore, based on the high hardness and high strength, $A l$ alloys showed a high ballistic efficiency. Most of the projectile was intact inside the $A l$ alloys. Contrarily, the $M g$ alloys comprise of a low hardness and low mechanical strength. Therefore, the projectile completely perforated. However, the low density of the $M g$ alloys is very attractive; therefore, the ballistic impact resistance of $\mathrm{Mg}$ alloys is of special interest. 

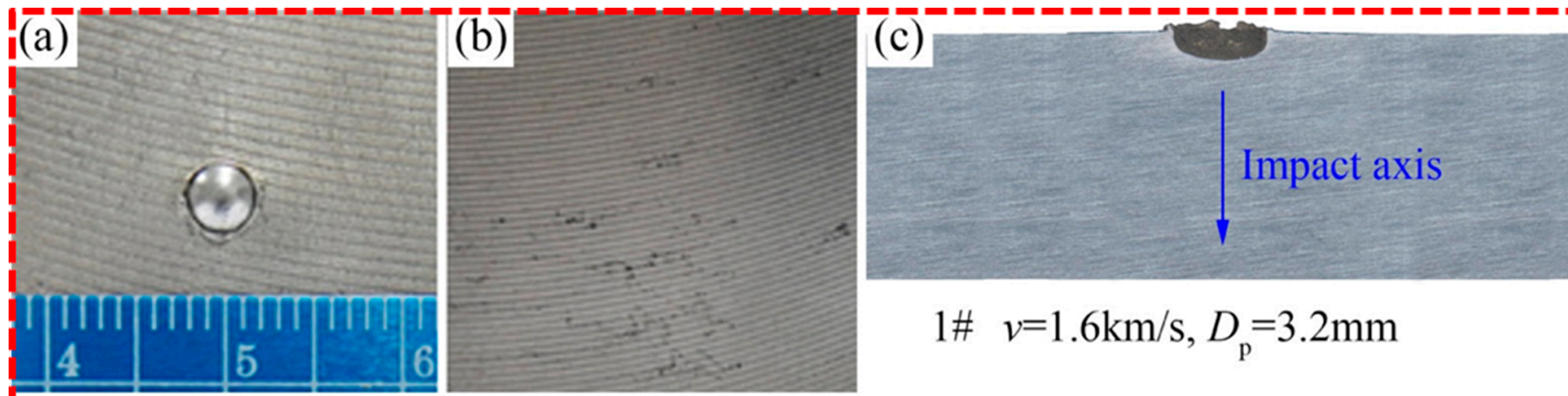

$1 \# v=1.6 \mathrm{~km} / \mathrm{s}, D_{\mathrm{p}}=3.2 \mathrm{~mm}$
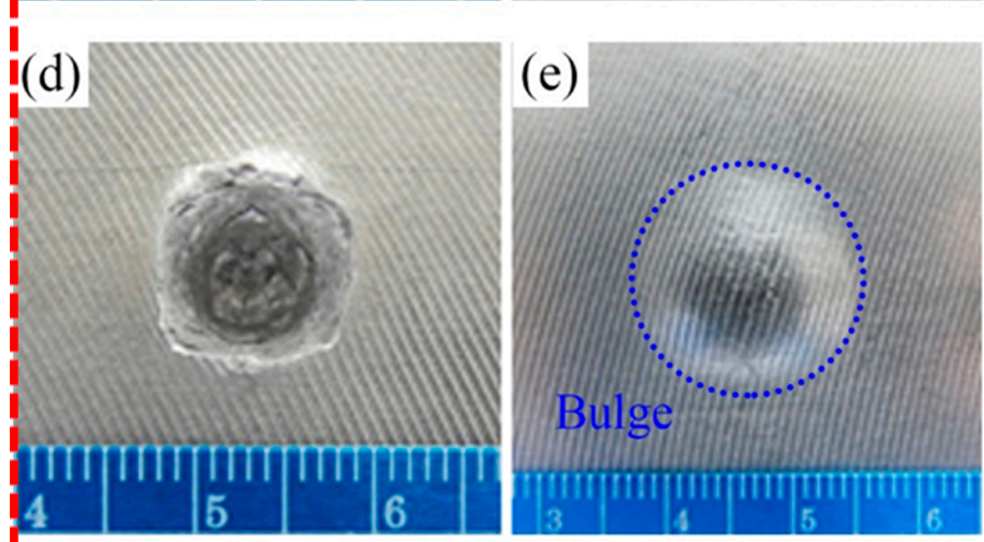

(f)

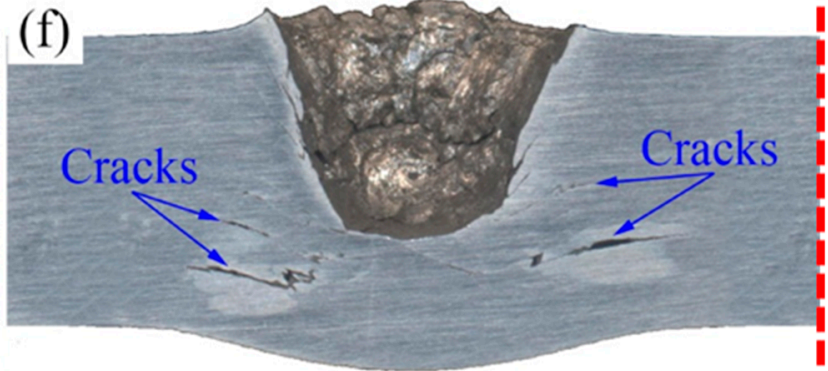

$2 \# v=3.8 \mathrm{~km} / \mathrm{s}, D_{\mathrm{p}}=3.2 \mathrm{~mm}$

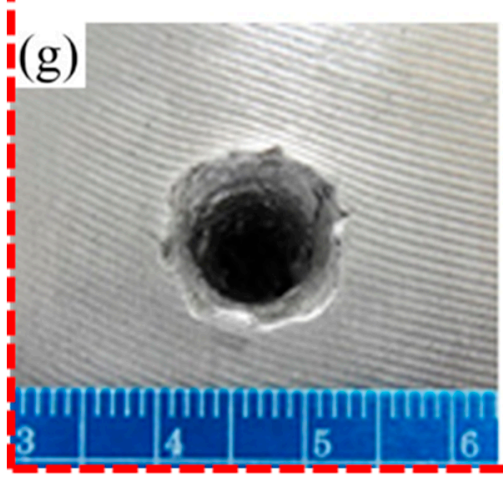

(h)

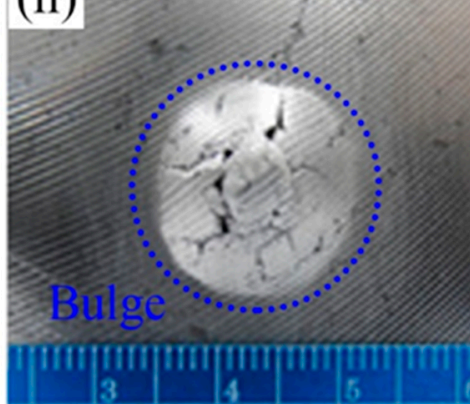

(i)
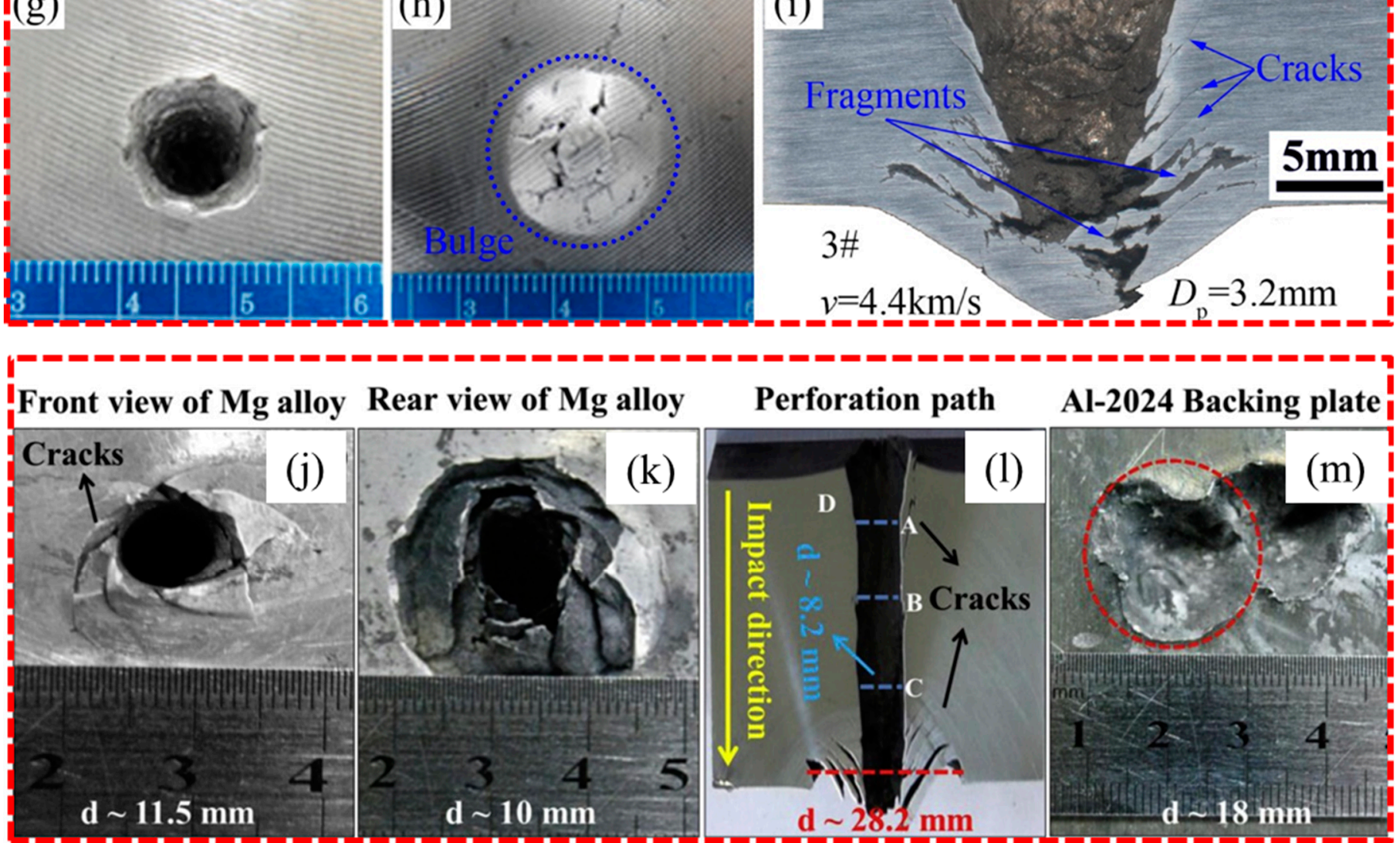

Figure 1. The macro images of deformed specimens: (a-i) $A Z 31 \mathrm{Mg}$ alloy at given conditions against 2017 Al projectile [27] (Copyright 2022 Elsevier); (j-m) front and rear view, perforation channel and backing plate images of $\mathrm{Mg}-\mathrm{Zn}-\mathrm{Zr} \mathrm{Mg}$ alloy (thickness $30 \mathrm{~mm}$ ) against standard $7.62 \mathrm{~mm}$ soft steel core projectile under standard velocity $830 \mathrm{~m} / \mathrm{s}$ [17] (Copyright 2022 Elsevier). 
Almost all aforementioned studies on $M g$ alloys reported a rotational dynamic recrystallization mechanism to accommodate the stress-energy under ballistic impact loading. A comprehensive microstructure evolution after the ballistic impact loading was presented in our previous review article [33]. However, the ballistic impact resistance at a standard velocity of $830 \mathrm{~m} / \mathrm{s}$ or hypervelocity $1200 \mathrm{~m} / \mathrm{s}$ with a standardized projectile (soft steel core deformable blunt projectile or hard steel core non-deformable API projectile) against an $M g$ alloy sheet is still an open question. Here, in this study, we propose a novel approach "cross pre-compression" for developing a lightweight high-strength $\mathrm{Mg}$ alloy, which can provide ballistic impact resistance against standardized $7.62 \mathrm{~mm}$ soft steel or hard steel core projectiles under a standard velocity of $830 \mathrm{~m} / \mathrm{s}$.

\section{Proposed Solution and Anticipated Deformation Mechanism}

The $Z K$ series of $M g$ alloys are of special interest in terms of their large ductility and mechanical strength compared to other $M g$ series [34]. The root cause of the strong and ductile $Z K$-based $M g$ alloy is the incorporation of zirconium $(Z r)$, which is a potent grain refiner and can stabilize the $M g Z n_{2}$ precipitates. Given their potential, an extruded $Z K$-based $\mathrm{Mg}$ alloy of dimensions $100 \mathrm{~mm} \times 100 \mathrm{~mm} \times 30 \mathrm{~mm}$ would be required to subject against the heat treatment process $\left(510^{\circ} \mathrm{C}\right.$ for $7-8 \mathrm{~h}$ ), so that the finer grains can recrystallize into big equiaxed grains (greater than or equal to $15 \mu \mathrm{m}$ ). Later, the aging process under a temperature of $180^{\circ} \mathrm{C}$ for $6-12 \mathrm{~h}$ would also be required. The reason for increasing the grain's size is that twinning induces deformation, which hardly occurs in fine small grains. Subsequently, the material can be subjected to cross pre-compression for imparting twinning, dislocation, and altering the texture as shown in Figure 2. The suitable pre-compression parameters for ZK-based $M g$ alloys (extruded ZK61 Mg alloy) under extrusion conditions should be pre-strained up to 0.1 at room temperature under a strain rate of $0.001 / \mathrm{s}$ [35]. It is obvious that twinning is strain path-dependent, i.e., loading along with the $E D$ and $T D$ can produce twinning-induced deformation in extruded $M g$ alloys with a c-axes//ND texture of the sheet. Therefore, the loading along with the $E D$ and, subsequently, the loading along with the $N D$ brings out a de-twinning phenomenon as reported in Ref. [36]. Therefore, the practically possible pre-compression along with the $E D$ and then the TD is a realistic approach for retaining twinning. The texture (c-axes//ND) of an undeformed extruded $M g$ alloy can be altered towards c-axes//ED under loading along with the $E D$ (soft orientation) up to a strain of 0.1 , while, again, loading along with the $T D$ (soft orientation) is also advantageous for twinning-induced deformation, and would rotate the $c$-axes of the grains towards the c-axes//TD as schematically illustrated in Figure 2.

The pre-compression can be applied in two different directions up to higher strains. Therefore, some of the grains would be engulfed by twinning, and can completely alter the a-axis distribution. However, some of them would be left or tilted towards the ED of the sheet; later, loading along with the TD would also tilt some of the grains and some of them would be engulfed through twinning. Moreover, some of the twinned grains would, preferentially, exhibit de-twinning, owing to different twin variants and twinning morphology (individual lenticular twin in a single grain, neighbor twinning, and chain twinning) [37]. Hence, finally, a resultant texture (c-axes $\perp N D$ or tilted away from the $N D$ and random distribution of $a$-axes) can be developed at the end of the pre-straining.

In our previous review article [14], it was summarized that the pre-strain level increased the yield strength $(Y S)$ of the $M g$ alloys; therefore, the strain up to 0.1 led to a remarkable increase in the $Y S$ of the $Z K$-based $M g$ alloy. The texture c-axes $\perp N D$ and the loading along with the ND led to the sigmoidal shape curve, which is the signature of twinning-induced deformation; however, the sigmoidal shape curve correlates with the twinning and de-twinning phenomenon [35,38-41]. In addition, twinning boundaries subdivide the parent grains into the number of grains, especially in an multi-variant extension twinning alloy, which can also facilitate the increase in the compressive yield strength (CYS) [14]. Figure 3 illustrates the CYS and UCS of some $M g$ alloys subjected to pre-straining under different conditions. The graph reflects that the pre-straining was 
beneficial for enhancing the CYS and UCS simultaneously. This is related to the grain refinement through pre-induced twinning boundaries, high residual stresses/dislocation [42], and the obvious reallocation of the precipitates from basal to prismatic and prismatic to basal slip, which can facilitate more resistance during plastic deformation [43,44]. The other reason is the high $<a>$ basal Schmidt factor $(S F)$ in the pre-compressed $\mathrm{Mg}$ alloy and can be attributed to the altered texture. The alloy is also in a pre-compressed state; therefore, the dislocation cannot be neglected, which also contributes to the increase in the CYS. Therefore, twinning, de-twinning, hard texture orientations, and the dislocation-twin interaction leads to a high UCS. Not only the CYS and UCS, but also the hardness of the $M g$ alloys can be increased, which correlates with the synergistic effect of twinning boundaries and pre-induced dislocation.

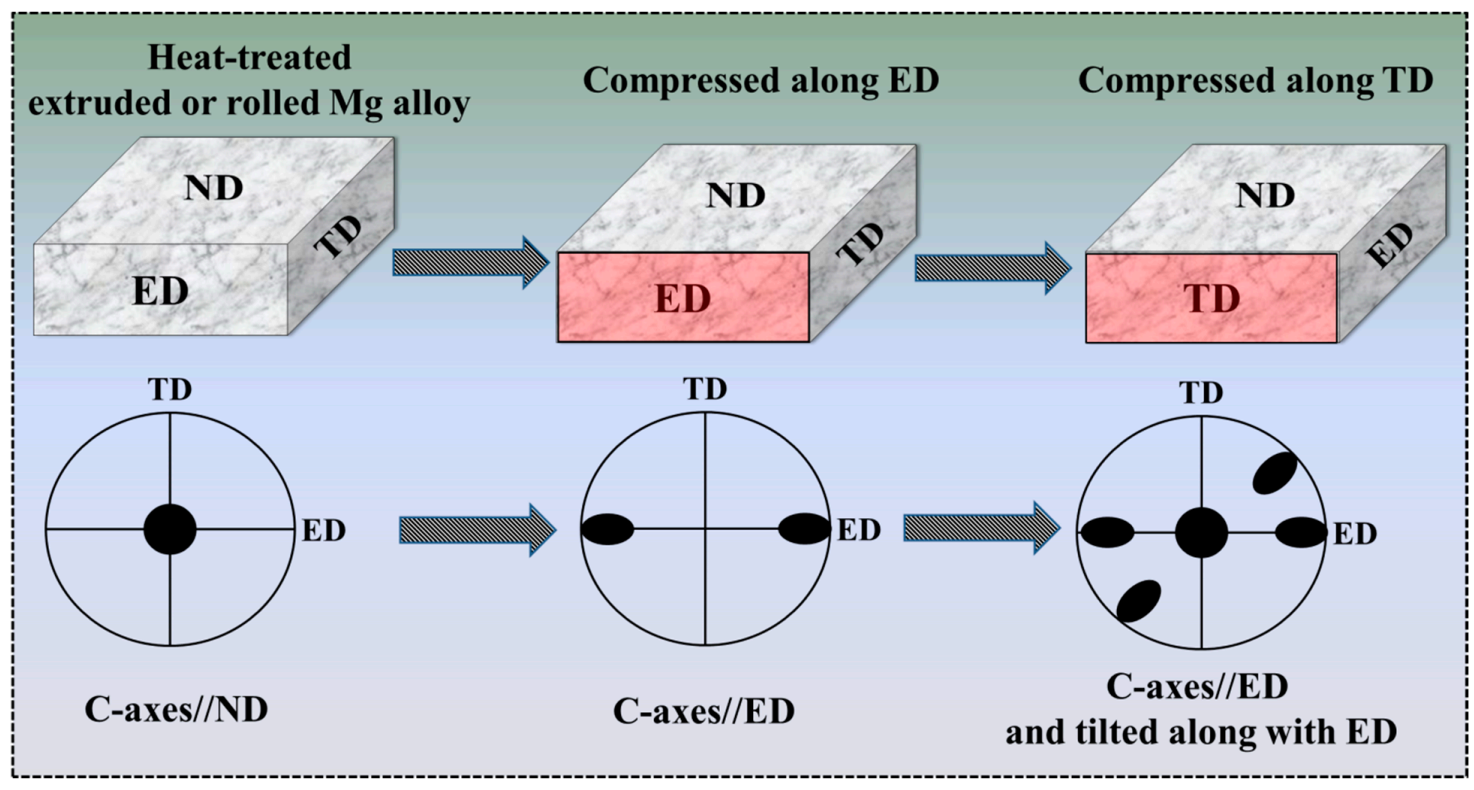

Figure 2. Schematic illustration of pre-compression process and texture of $M g$ alloys.

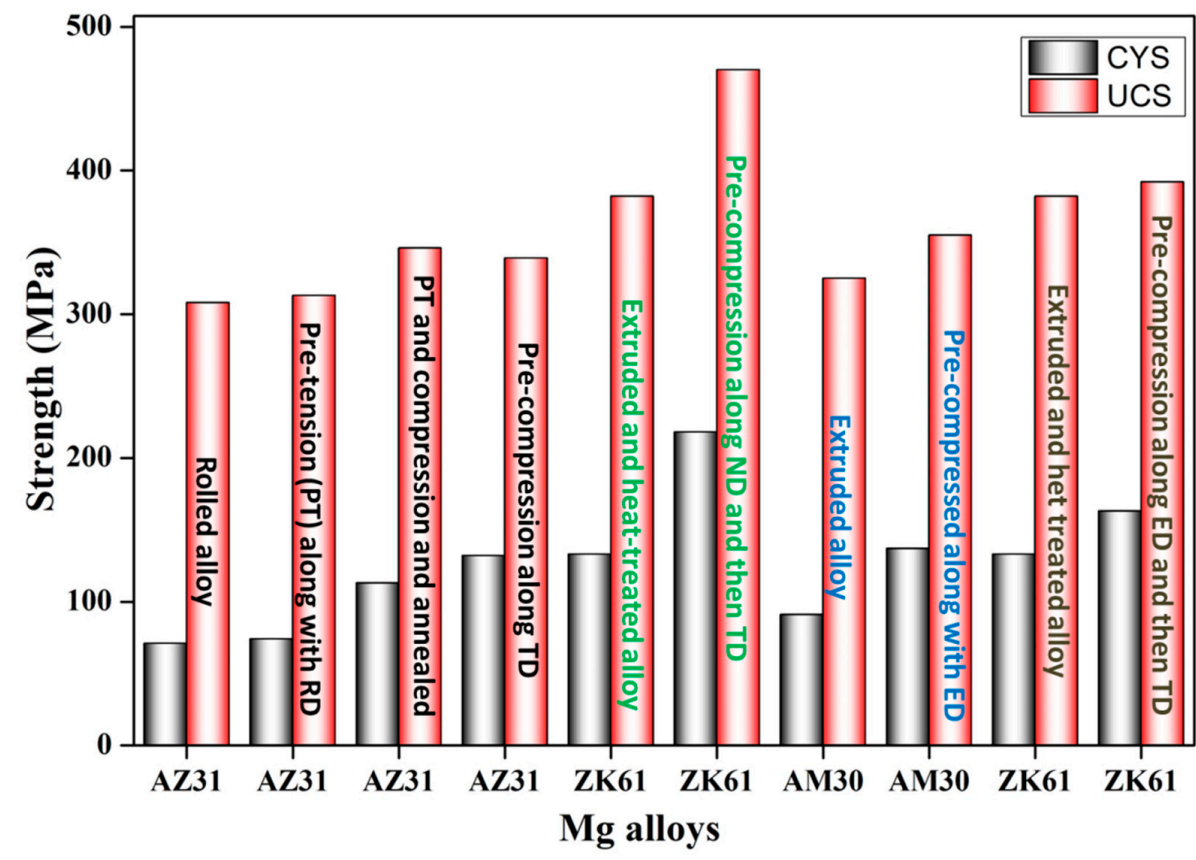

Figure 3. The different $M g$ alloys subjected to pre-straining under different loading conditions [35,38,39]. 
The mechanical response of the $M g$ alloys under a high strain rate compression differed to the quasi-static compressive loading [37]. In prior literature, it was proposed that the alloys which provide both dislocation and twinning-assisted deformation were strain rate sensitive [18]. The UCS of those alloys increased with an increase in the strain until thermal softening overcame the UCS. Therefore, the cross pre-compressed $M g$ alloy having a different texture and pre-induced twinning and dislocation provided a higher strain rate sensitivity under ballistic impact. The other reason was the higher slip activity under loading along with the $N D$ of the cross pre-compressed specimen compared to the quasi-static loading. The texture $c$-axes $\perp N D$ or tilted away from the $N D$ and the random distribution of a-axes are liable to produce a higher $S F$ value for the $\{0002\}<11 \overline{2} 0>$ basal slip, which can produce ease in an extensive basal glide in contrast to the strong basal texture $(c$-axes//ND). In short, the higher $\{0002\}<11 \overline{2} 0>$ basal slip activity under dynamic compressive loading is texture advantageous for twinning and de-twinning and, further, its interaction with the dislocation and re-allocation of hard precipitates on the basal plane leads to a higher dynamic CYS and UCS. Thus, the synergistic effect of a high $U C S$, high CYS, high hardness, and texture (c-axes $\perp N D$ or tilted away from the $N D)$ could be beneficial for absorbing more stress-energy against a standardized $7.62 \mathrm{~mm}$ projectile (soft and hard) and might stay intact inside of the magnesium targeted alloy.

The twinning induces the rotational dynamic recrystallization mechanism along with the adiabatic shear band and cracks accommodate the stress-energy near to the crater after ballistic impact in $M g$ alloys, as reported in Refs. [17,33]. The microstructure away from the crater comprised of different zones, such as the ultrafine grain zone (UFGZ), ultrafine grain and twinning zone (UFG and TZ), high-density deformation twinning zone (HDDTZ), and low-density deformation twining zone (LDDTZ), as shown in Figure 4a. This showed the gradient variation of the strain energy away from the crater. Notably, the pre-compressed $\mathrm{Mg}$ alloys already contained profuse HDDTs as illustrated in Figure 4b [45]. Thus, it is anticipated that the already pre-induced twinning through pre-compression would also facilitate a large volume fraction of ultrafine grains on further impact adjacent and away from the crater. The pre-induce twinning interacts with the newly developed twinning in the early stages of impact and with impact proceeding, a twin-twin interaction, the detwinning/annihilation of twinning, and the interaction with dislocation lead to a dynamic recrystallization. It was noted that the twinning areas already contained high residual stresses, and offered new sites for grain refinement, especially for the $\{10 \overline{1} 1\}<10 \overline{1} 2>$ contraction twinning and $\{10 \overline{1} 1\}-\{10 \overline{1} 2\}$ double twinning.

It is also obvious that the high-speed impact leads to a temperature rise, which facilitates the activation of a higher $\langle c+a\rangle$ non-basal slip activity owing to a decrease in their CRSS. Therefore, $<a>$ basal, $<a>$ prismatic, and $<c+a>$ non-basal (pyramidal I and pyramidal II), along with pre-induced twinning, can offer a maximum absorption capacity under a high strain rate impact. However, the critical stress-energy at the twin-twin interaction or dislocation pileup at the triple junction of fine newly nucleated grains might be higher, but this stress energy can be accommodated by the rise in temperature and, hence, the possibility of crack formation can be controlled near the crater in an already pre-twinned $\mathrm{Mg}$ alloy. Thus, an already high-density deformation twining zone in a pre-compressed $\mathrm{Mg}$ alloy can facilitate the attainment of finer grains and result in the formation of a large UFGZ as shown in Figure $4 \mathrm{~b}$. Moreover, this zone can provide more resistance to the next impact, which can be adjacent to the first impact. In the literature [17], it has already been reported that the texture near the crater is strong prismatic (c-axes $\perp N D)$, and the hardness in UFGs is also high; hence, this type of texture would exhibit a sigmoidal-shaped curve and would produce more resistance through the strain hardening of the alloy; therefore, due to the UFGZ and high hardness, the second projectile would also experience a high resistance by the targeted material. Thus, pre-induced twinning can lead to only three zones, UFGZ, UFG and TZ, and HDDTZ (Figure 4b), compared to the twin-free $M g$ alloys which exhibit the UFGZ, UFG and TZ, HDDTZ, LDDTZ and unaffected zone (Figure 4a). 


\section{Non-pre-compressed $M g$ alloy}

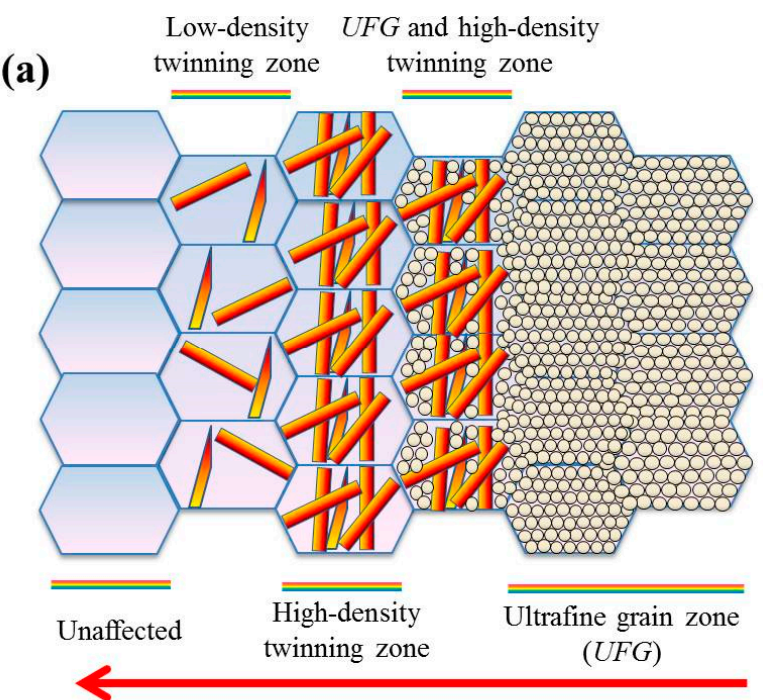

Pre-compressed $M g$ alloy

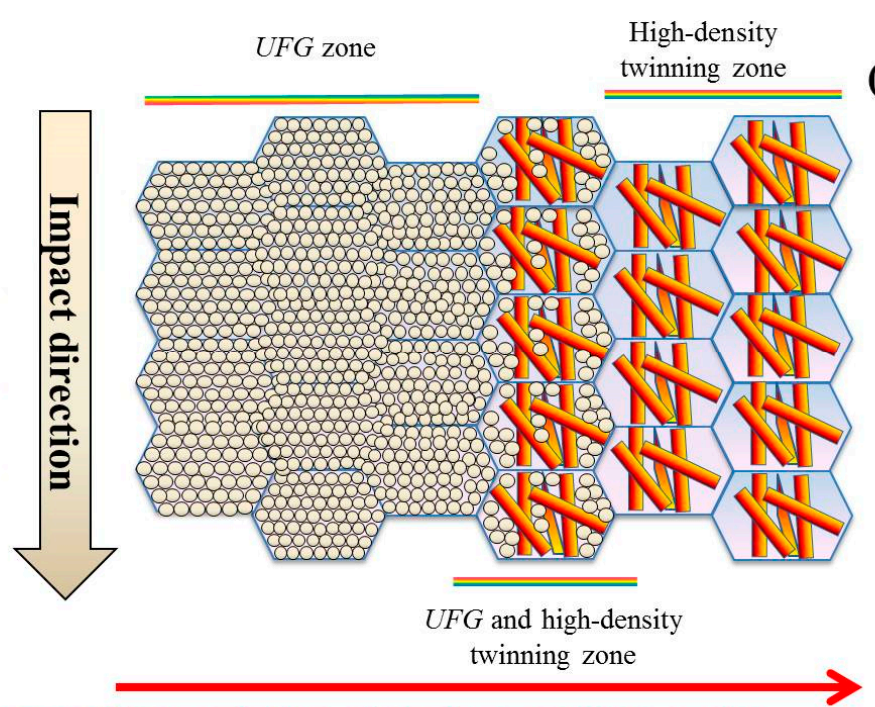

Broad side of the crater illustrating gradient variation of strain away from crater

Figure 4. Schematic illustration of the anticipated deformation mechanism after the ballistic impact of (a) non-pre-compressed (b) pre-compressed $M g$ alloy.

Based on the twinning dependencies on the strain path loading and then their role on the strain hardenability, the optimization of the texture $(c$-axes $\perp N D)$ for compression loading along the ND is advantageous. Therefore, cross pre-compression is beneficial for increasing strength compared to die-casted and thermomechanically processed $\mathrm{Mg}$ alloys. The ballistic impact resistance and the deformation mechanism of die-casted, thermomechanically processed, and pre-compressed $M g$ alloys are illustrated in Figure 5. In short, the (c-axes $\perp N D)$ texture through cross pre-compression, profuse pre-induced twinning, high dislocation activity, the interaction of dislocation and twinning, twin annihilation, and high hardness can absorb the stress-energy of the projectile and can stop it inside of the target.
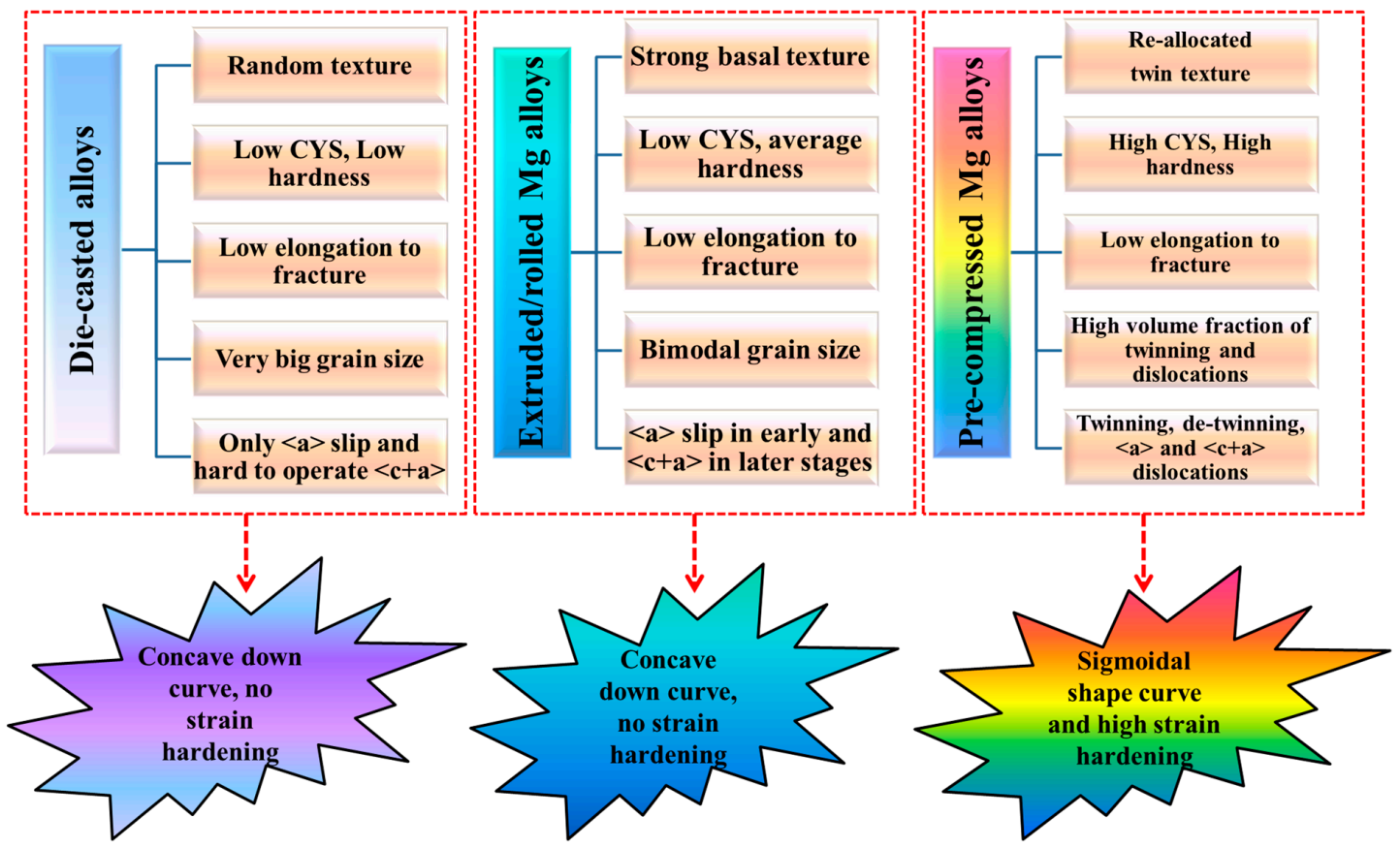

Figure 5. Schematic illustration of texture, strength, elongation, slips, and deformation mechanism in differently processed $\mathrm{Mg}$ alloys. 


\section{Conclusions}

In this study, we proposed a possible solution for the ballistic impact resistance of lightweight $M g$ alloys. The following important points are summarized below:

1. The typical extruded/rolled texture (c-axes//ND) cannot facilitate a large strain hardening ability, owing to twinning dependencies on the strain path loading. After cross pre-compression, multiple extension twin variants and extension twin types can re-distribute the texture towards $c-$ axes $\perp N D$ and tilted towards the ND. This crystallographic orientation under projectile impact loading along with the normal direction can provide a high strain hardening ability.

2. The grain refinement through twinning boundaries can increase the compressive yield strength, ultimate compression strength, and hardness of the $\mathrm{Mg}$ alloy. The high ultimate compression strength is the cause of de-twinning and the twin-dislocation interaction.

3. The high hardness can control the depth of the penetration, while high mechanical properties can show a high absorption capacity. Consequently, strong resistance against the projectile impact can be offered.

4. The re-allocation of non-basal precipitates to the basal plane and vice versa can also take parts to increase the strength. The basal slip activity and non-basal slip activity and its interaction with the pre-induced twinning can lead to a large UFGZ, which can provide more resistance against the next projectile under the impact adjacent to the first crater.

The optimization of the texture and microstructure features through this practical "cross pre-compression" technique can increase the use of $M g$ alloys in aerospace and military industries.

Author Contributions: A.M.: Investigation, Formal analysis, Data curation, Visualization, Writing—original draft. F.N.: Visualization, Conceptualization, Writing—review \& editing. Y.W.: Supervision, Conceptualization, Writing-review \& editing, Funding acquisition. All authors have read and agreed to the published version of the manuscript.

Funding: This research was supported by the National Natural Science Foundation of China, Guangxi Joint Fund (U20A20276).

Data Availability Statement: Not applicable.

Acknowledgments: This research was supported by the National Natural Science Foundation of China, Guangxi Joint Fund (U20A20276).

Conflicts of Interest: The authors declare that they have no known competing financial interest or personal relationships that could have appeared to influence the work reported in this paper.

\section{References}

1. Di Benedetto, G.; Matteis, P.; Scavino, G. Impact behavior and ballistic efficiency of armor-piercing projectiles with tool steel cores Int. J. Impact Eng. 2018, 115, 10-18. [CrossRef]

2. Khan, M.A.; Wang, Y.; Cheng, H.; Yasin, G.; Malik, A.; Nazeer, F.; Ahmad, T.; Khan, W.Q.; Kamran, M.; Afifi, M.A. Microstructure evolution of an artificially aged Al-Zn-Mg-Cu alloy subjected to soft- and hard-steel core projectiles. J. Mater. Res. Technol. 2020, 9 , 11980-11992. [CrossRef]

3. Zheng, C.; Wang, F.; Cheng, X.; Liu, J.; Fu, K.; Liu, T.; Zhu, Z.; Yang, K.; Peng, M.; Jin, D. Failure mechanisms in ballistic performance of Ti-6Al-4V targets having equiaxed and lamellar microstructures. Int. J. Impact Eng. 2015, 85, 161-169. [CrossRef]

4. Malik, A.; Wang, Y.; Huanwu, C.; Bhatti, T.M.; Nazeer, F. Superplastic behavior of fine-grained extruded ZK61 Mg alloy. Results Phys. 2021, 20, 103731. [CrossRef]

5. Nazeer, F.; Long, J.; Yang, Z.; Li, C. Superplastic deformation behavior of Mg alloys: A-review. J. Magnes. Alloys 2021. [CrossRef]

6. Park, J.-H.; Kim, S.-H.; Kim, S.-G.; Kim, H.-W.; Lee, J.-C. Improved cryogenic properties of the Al-xMg alloys enabled by twin-roll strip casting. J. Mater. Res. Technol. 2021, 13, 1285-1295. [CrossRef]

7. Chaudry, U.M.; Hamad, K.; Kim, J.-G. On the ductility of magnesium based materials: A mini review. J. Alloys Compd. 2019, 792, 652-664. [CrossRef]

8. Malik, A.; Wang, Y.; Nazeer, F.; Khan, M.A.; Sajid, M.; Jamal, S.; Mingjun, W. Deformation behavior of Mg-Zn-Zr magnesium alloy on the basis of macro-texture and fine-grain size under tension and compression loading along various directions. J. Alloys Compd. 2021, 858, 157740. [CrossRef] 
9. Xiong, Y.; Yu, Q.; Jiang, Y. Deformation of extruded ZK60 magnesium alloy under uniaxial loading in different material orientations. Mater. Sci. Eng. A 2018, 710, 206-213. [CrossRef]

10. Chen, X.; Xiao, L.; Liu, Y.; Xu, M.; Xu, T.; Gao, B.; Hu, Z.; Zhou, H. High strength-ductility of heterogeneous sandwich Mg-Y alloys produced by high pressure torsion. Vacuum 2020, 179, 109568. [CrossRef]

11. Chaudry, U.M.; Kim, T.H.; Park, S.D.; Kim, Y.S.; Hamad, K.; Kim, J.-G. Effects of calcium on the activity of slip systems in AZ31 magnesium alloy. Mater. Sci. Eng. A 2019, 739, 289-294. [CrossRef]

12. Chaudry, U.M.; Kim, Y.S.; Hamad, K. Effect of Ca addition on the room-temperature formability of AZ31 magnesium alloy. Mater Lett. 2019, 238, 305-308. [CrossRef]

13. Malik, A.; Masood Chaudry, U.; Hamad, K.; Jun, T.-S. Microstructure Features and Superplasticity of Extruded, Rolled and SPD-Processed Magnesium Alloys: A Short Review. Metals 2021, 11, 1766. [CrossRef]

14. Malik, A.; Wang, Y.; Nazeer, F.; Khan, M.A.; Ali, T.; Ain, Q.T. Effect of pre-straining on twinning, texture and mechanical behavior of magnesium alloys A-review. J. Mater. Res. Technol. 2020, 9, 14478-14499. [CrossRef]

15. Zang, Q.; Chen, H.; Zhang, J.; Wang, L.; Chen, S.; Jin, Y. Microstructure, mechanical properties and corrosion resistance of AZ31/GNPs composites prepared by friction stir processing. J. Mater. Res. Technol. 2021, 14, 195-201. [CrossRef]

16. Luo, X.; Feng, Z.; Yu, T.; Luo, J.; Huang, T.; Wu, G.; Hansen, N.; Huang, X. Transitions in mechanical behavior and in deformation mechanisms enhance the strength and ductility of Mg-3Gd. Acta Mater. 2020, 183, 398-407. [CrossRef]

17. Malik, A.; Wang, Y.; Cheng, H.; Nazeer, F.; Khan, M.A. Microstructure evolution of Mg-Zn-Zr magnesium alloy against soft steel core projectile. J. Mater. Sci. Technol. 2021, 79, 46-61. [CrossRef]

18. Malik, A.; Yangwei, W.; Huanwu, C.; Khan, M.A.; Nazeer, F.; Rui, A.; Jiawei, B.; Mingjun, W. Fracture behavior of twin induced ultra-fine grained ZK61 magnesium alloy under high strain rate compression. J. Mater. Res. Technol. 2019, 8, 3475-3486. [CrossRef]

19. Abdullah, M.F.; Abdullah, S.; Omar, M.Z.; Sajuri, Z.; Sohaimi, R.M. Failure observation of the AZ31B magnesium alloy and the effect of lead addition content under ballistic impact. Adv. Mech. Eng. 2015, 7, 1687814015585428. [CrossRef]

20. Chaudry, U.M.; Kim, T.H.; Kim, Y.S.; Hamad, K.; Ko, Y.G.; Kim, J.-G. Dynamic recrystallization behavior of AZ31-0.5Ca magnesium alloy during warm rolling. Mater. Sci. Eng. A 2019, 762, 138085. [CrossRef]

21. Zhen, L.; Zou, D.L.; Xu, C.Y.; Shao, W.Z. Microstructure evolution of adiabatic shear bands in AM60B magnesium alloy under ballistic impact. Mater. Sci. Eng. A 2010, 527, 5728-5733. [CrossRef]

22. Zou, D.L.; Zhen, L.; Xu, C.Y.; Shao, W.Z. Characterization of adiabatic shear bands in AM60B magnesium alloy under ballistic impact. Mater. Charact. 2011, 62, 496-502. [CrossRef]

23. Zou, D.L.; Zhen, L.; Zhu, Y.; Xu, C.Y.; Shao, W.Z.; Pang, B.J. Deformed microstructure and mechanical properties of AM60B magnesium alloy under hypervelocity impact at a velocity of $4 \mathrm{kms}^{-1}$. Mater. Sci. Eng. A 2010, 527, 3323-3328. [CrossRef]

24. Zou, D.L.; Zhen, L.; Zhu, Y.; Xu, C.Y.; Shao, W.Z.; Pang, B.J. Deformed microstructure evolution in AM60B Mg alloy under hypervelocity impact at a velocity of $5 \mathrm{kms}^{-1}$. Mater. Des. 2010, 31, 3708-3715. [CrossRef]

25. Zhang, B.; Jiang, J.-T.; Liu, L.; Shao, W.-Z.; Zhen, L. Texture evolution and recrystallization mechanism in a Mg-3Al-1Zn alloy under ballistic impact. J. Alloys Compd. 2020, 816, 152599. [CrossRef]

26. Zhang, B.; Jiang, J.-T.; Liu, L.; Li, G.-A.; Shao, W.-Z.; Zhen, L. Highly localized shear deformation in a Mg-Al-Mn alloy subjected to ballistic impact. Vacuum 2019, 169, 108868. [CrossRef]

27. Zhang, W.; Li, K.; Chi, R.; Tan, S.; Li, P. Insights into microstructural evolution and deformation behaviors of a gradient textured AZ31B Mg alloy plate under hypervelocity impact. J. Mater. Sci. Technol. 2021, 91, 40-57. [CrossRef]

28. Shi, X.; Luo, A.A.; Sutton, S.C.; Zeng, L.; Wang, S.; Zeng, X.; Li, D.; Ding, W. Twinning behavior and lattice rotation in a Mg-Gd-Y-Zr alloy under ballistic impact. J. Alloys Compd. 2015, 650, 622-632. [CrossRef]

29. Duan, S.; Guo, F.; Zhang, Y.; Chong, K.; Lee, S.; Matsuda, K.; Zou, Y. Effects of texture and precipitates characteristics on anisotropic hardness evolution during artificial aging for an Al-Cu-Li alloy. Mater. Des. 2021, 212, 110216. [CrossRef]

30. Khan, M.A.; Wang, Y.; Cheng, H.; Nazeer, F.; Yasin, G.; Farooq, M.U.; Malik, A.; Nazir, Z. Ballistic behaviour of spray formed AA7055 aluminum alloy against tungsten core projectile impact. Vacuum 2019, 159, 482-493. [CrossRef]

31. Khan, M.A.; Wang, Y.; Yasin, G.; Malik, A.; Nazeer, F.; Khan, W.Q.; Zhang, H.; Ahmed, T. Microstructure characteristic of spray formed $7055 \mathrm{Al}$ alloy subjected to ballistic impact by two different steel core projectiles impact. J. Mater. Res. Technol. 2019, 8 , 6177-6190. [CrossRef]

32. Khan, M.A.; Wang, Y.; Malik, A.; Nazeer, F.; Yasin, G.; Khan, W.Q.; Ahmad, T.; Zhang, H. Microstructure characterization of 7055-T6, 6061-T6511 and 7A52-T6 Al alloys subjected to ballistic impact against heavy tungsten alloy projectile. Arch. Civ. Mech. Eng. 2019, 19, 1484-1496. [CrossRef]

33. Malik, A.; Wang, Y.; Huanwu, C.; Nazeer, F.; Khan, M.A. Post deformation analysis of the ballistic impacted magnesium alloys, a short-review. J. Magnes. Alloys 2021, 9, 1505-1520. [CrossRef]

34. Malik, A.; Wang, Y.; Nazeer, F. The development of a strong and ductile $\mathrm{Mg}-\mathrm{Zn}-\mathrm{Zr}$ thin sheet through nano precipitates and pre-induced dislocation. Mater. Sci. Eng. A 2021, 817, 141339. [CrossRef]

35. Malik, A.; Wang, Y.; Nazeer, F.; Khan, M.A. Effect of pre-compression on changes in texture and yielding behavior of ZK61 Mg alloy. Vacuum 2020, 172, 109039. [CrossRef]

36. Mokdad, F.; Chen, D.; Li, D. Twin-twin interactions and contraction twin formation in an extruded magnesium alloy subjected to an alteration of compressive direction. J. Alloys Compd. 2018, 737, 549-560. [CrossRef] 
37. Malik, A.; Chaudry, U.M.; Yan, T.; Long, J.; Li, C.; Wang, Y. Achieving higher dynamic mechanical response by adjusting texture through twinning in a ZK61 Mg alloy. J. Alloys Compd. 2022, 902, 163755. [CrossRef]

38. Song, B.; Xin, R.; Zheng, X.; Chen, G.; Liu, Q. Activation of multiple twins by pre-tension and compression to enhance the strength of Mg-3Al-1Zn alloy plates. Mater. Sci. Eng. A 2015, 621, 100-104. [CrossRef]

39. Sarker, D.; Friedman, J.; Chen, D.L. Influence of pre-deformation and subsequent annealing on strain hardening and anisotropy of AM30 magnesium alloy. J. Alloys Compd. 2014, 611, 341-350. [CrossRef]

40. Malik, A.; Wang, Y.; Nazeer, F. The both positive and negative effect of pre-strain on the mechanical response of extruded magnesium alloy. Forces in Mechanics 2021, 4, 100031. [CrossRef]

41. Long, J.; Nazeer, F.; Yang, Z.; Li, C. Compressive properties, mechanical anisotropy and hardness analysis of Mg-Zn alloy under cross pre-compression. Arch. Civ. Mech. Eng. 2021, 21, 156. [CrossRef]

42. Wang, M.; He, B.B.; Huang, M.X. Strong and ductile Mg alloys developed by dislocation engineering. J. Mater. Sci. Technol. 2019, 35, 394-395. [CrossRef]

43. Wan, Y.J.; Zeng, Y.; Dou, Y.C.; Hu, D.C.; Qian, X.Y.; Zeng, Q.; Sun, K.X.; Quan, G.F. Improved mechanical properties and strengthening mechanism with the altered precipitate orientation in magnesium alloys. J. Magnes. Alloys 2021. [CrossRef]

44. Wang, X.J.; Xu, D.K.; Wu, R.Z.; Chen, X.B.; Peng, Q.M.; Jin, L.; Xin, Y.C.; Zhang, Z.Q.; Liu, Y.; Chen, X.H.; et al. What is going on in magnesium alloys? J. Mater. Sci. Technol. 2018, 34, 245-247. [CrossRef]

45. Yang, Q.; Jiang, B.; Song, B.; Yu, Z.; He, D.; Chai, Y.; Zhang, J.; Pan, F. The effects of orientation control via tension-compression on microstructural evolution and mechanical behavior of AZ31 Mg alloy sheet. J. Magnes. Alloys 2020. [CrossRef] 